\title{
CANADIAN LIGHT SOURCE MAGNETS
}

\section{Dallin, D. Lowe, J. Swirsky, Canadian Light Source, University of Saskatchewan, 101 Perimeter Road, Saskatoon, Saskatchewan, S7N 0X4, Canada}

\section{Abstract}

Magnets for the Canadian Light Source (CLS) storage ring have been designed and constructed. Magnets include gradient dipoles, quadrupoles, sextupoles, orbit correctors, injection septum and kickers. The compact CLS lattice requires strong focusing and consequently field gradients approach the upper limit of conventional magnet technology. Magnets have been manufactured by industry at a variety of locations. Prototypes have been developed and measured and meet the requirements set out in the magnet specifications. A description of the CLS quadrupole, sextupole and corrector magnets and magnet measurement results will be presented.

\section{DIPOLE MAGNETS}

The CLS [1] requires 24 gradient dipole magnets. These magnets were built at TESLA Engineering in Storrington, U.K. and are described in ref. [2].

\section{QUADRUPOLE MAGNETS}

The CLS requires three families of quadrupole magnets. Two families have the same design. The third family has the same design but is about $50 \%$ longer. Parameters are given in Table 1.

Table 1 Quadrupole Design Parameters.

\begin{tabular}{|c|c|c|c|c|c|}
\hline Name & \multicolumn{2}{|c|}{ QFA/QFB } & \multicolumn{2}{|c|}{ QFC } & \\
\hline \#Magnets & \multicolumn{2}{|c|}{48} & \multicolumn{2}{|c|}{24} & \\
\hline Field (max) & \multicolumn{2}{|c|}{22.2} & \multicolumn{2}{|c|}{22.2} & $\mathrm{~T} / \mathrm{m}$ \\
\hline Length & \multicolumn{2}{|c|}{0.170} & \multicolumn{2}{|c|}{0.253} & $\mathrm{~m}$ \\
\hline Aperture $\varnothing$ & \multicolumn{2}{|c|}{0.065} & \multicolumn{2}{|c|}{0.065} & \\
\hline Coils & 4 Inner & 4 Outer & 4 Inner & 4 Outer & \\
\hline Turns / coil & 69 & 35 & 69 & 35 & $\mathrm{t}$ \\
\hline Current & \multicolumn{2}{|c|}{87.50} & \multicolumn{2}{|c|}{87.50} & $\mathrm{~A}$ \\
\hline Amp turns & \multicolumn{2}{|c|}{9100} & \multicolumn{2}{|c|}{9100} & A-t \\
\hline \multicolumn{6}{|c|}{ Conductor (per magnet) } \\
\hline area & \multicolumn{2}{|c|}{$4.76^{2}$} & \multicolumn{2}{|c|}{$4.76^{2}$} & $\mathrm{~mm}^{2}$ \\
\hline cooling Ø & \multicolumn{2}{|c|}{3.19} & \multicolumn{2}{|c|}{3.19} & $\mathrm{~mm}$ \\
\hline length & 180 & 108 & 226 & 130 & $\mathrm{~m}$ \\
\hline resistance & 220 & 132 & 276 & 159 & $\mathrm{~m} \Omega$ \\
\hline Voltage & 19.2 & 11.5 & 24.1 & 13.9 & $\mathrm{~V}$ \\
\hline Power & 1.68 & 1.01 & 2.11 & 1.21 & $\mathrm{~kW}$ \\
\hline$\Delta \mathrm{T}$ of water & 8.00 & 3.48 & 11.1 & 4.55 & ${ }^{\circ} \mathrm{C}$ \\
\hline \multirow{2}{*}{ Water flow } & 3.0 & 4.2 & 2.7 & 3.8 & $\mathrm{~L} / \mathrm{m}$ \\
\hline & 0.80 & 1.1 & 0.72 & 1.0 & GPM \\
\hline
\end{tabular}

Pole tips are designed to minimize the multipole content of the magnets. Details of the geometry are given in ref. [3]. The sum of the higher order harmonics, inside a radial good field region of $\mathrm{r}<30 \mathrm{~mm}$, were required to satisfy the relationship:

$$
-0.002<\frac{\sum_{n=3}^{\infty} r^{n-1} \int B_{n}(l) d l}{r \int B^{\prime}(l) d l}<0.002
$$

where $B^{\prime}(l)$ and $B_{n}(l)$ are the quadrupole field and the $n^{\text {th }}$ harmonics along the magnet axis $(l)$.

The quadrupoles have a top yoke and a bottom yoke as shown in figure 1. The yokes are joined by two nonmagnetic end plates with an open-side construction that allows for a vacuum chamber with an antechamber for the passage of synchrotron light.

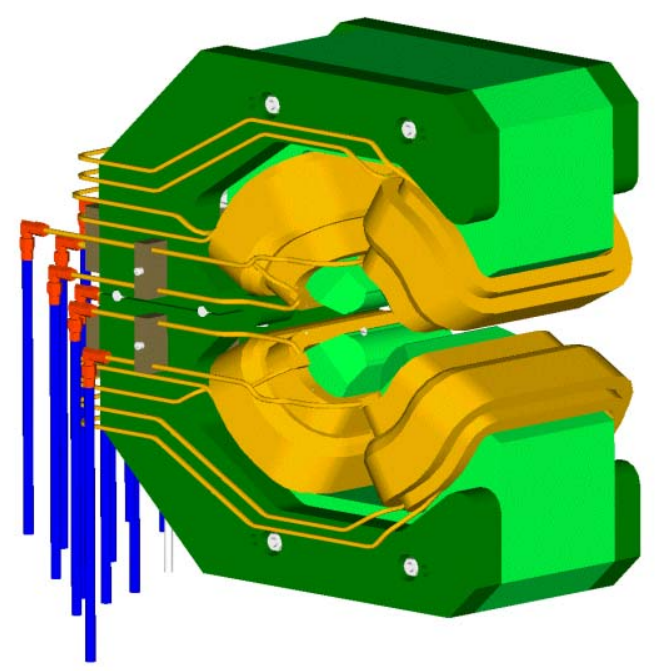

Figure 1. Isometric View of the Quadrupole Design.

The quadrupole magnets were built by SigmaPhi in Vannes, France. One of the finished magnets is shown in figure 2. The quadrupole is shown mounted on one of the CLS magnet girders. The stainless steel end plates also supply a precision interface to the machined girder for alignment.

All magnets from all three families were measured at SigmaPhi with a rotating coil assembly. Although a few of the magnets had higher order harmonics outside the specification defined in eq. (1), the average value of higher harmonics was much better than specified. Subsequent modelling of the CLS lattice with the "asbuilt" magnets indicated an improved lattice performance compared to the original harmonic estimates. 


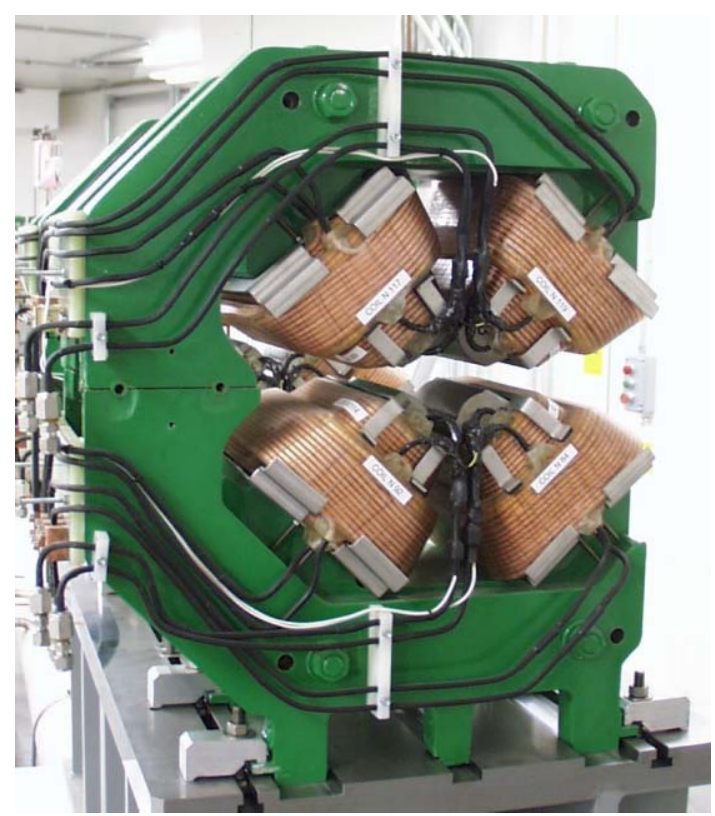

Figure 2. Fabricated Quadrupole Magnet.

For an example, the average harmonics for the QFA family of quadrupoles is shown in Table 2. In the table $I_{n / 2}$ is the integrated gradient strength of the $n^{\text {th }}$ harmonic relative to the integrated quadrupole gradient $\left(\mathrm{I}_{2}\right)$ in units of $\mathrm{m}^{-(\mathrm{n}-2)}$. Tilt indicates the rotation (skewness) of the harmonic in $\operatorname{mrads}\left[\mathrm{tilt}=\tan ^{-1}\right.$ (skew/normal)/(n-1)].

Table 2: Measured Harmonics for Family QFA

\begin{tabular}{|l|c|c|c|c|c|}
\hline $\mathrm{n}$ & 3 & 4 & 5 & 6 & 7 \\
\hline $\mathrm{I}_{\mathrm{n} / 2}$ & 0.0535 & 5.31 & $1.25 \mathrm{E} 2$ & $1.49 \mathrm{E} 4$ & $1.22 \mathrm{E} 6$ \\
\hline tilt & -297.4 & -15.3 & 1.97 & 3.98 & 1.58 \\
\hline $\mathrm{n}$ & 8 & 9 & 10 & 11 & 12 \\
\hline $\mathrm{I}_{\mathrm{n} / 2}$ & $2.65 \mathrm{E} 8$ & $6.18 \mathrm{E} 10$ & $3.55 \mathrm{E} 13$ & $3.21 \mathrm{E} 15$ & $1.12 \mathrm{E} 18$ \\
\hline tilt & 21.78 & -9.34 & -2.10 & 2.59 & 6.70 \\
\hline
\end{tabular}

\section{SEXTUPOLE MAGNETS}

The CLS requires two families of sextupoles, Family 1 has 24 magnets and family 2 has twelve. The yokes, mechanical assembly and sextupole field requirements for each family are the same. Family 1 also has separate coils for each of X-corrector, Y-corrector and skew quadrupole functions. Family 2 has extra coils for skew quadrupoles. The sextupole parameters are given in table 3 .

Details of the geometry are given in ref. [3]. The sum of the higher order harmonics, inside $\mathrm{r}<30 \mathrm{~mm}$, were required to satisfy:

$$
-0.01<\frac{\sum_{n=4}^{\infty} r^{n-1} \int B_{n}(l) d l}{r^{2} \int B_{3}(l) d l}<0.01
$$

where $B_{3}$ is the sextupole field. Similar, but more relaxed, requirements were specified for the corrector and skew quadrupole fields.

Table 3: Sextupole Design Parameters

\begin{tabular}{|l|c|c|}
\hline \# Magnets & 36 & \\
\hline Field (max) & 267.8 & $\mathrm{~T} / \mathrm{m}^{2}$ \\
\hline Length & 0.192 & $\mathrm{~m}$ \\
\hline Aperture $\varnothing$ & 0.078 & $\mathrm{~m}$ \\
\hline Coils & 6 & \\
\hline Turns/coil & 36 & $\mathrm{t}$ \\
\hline Max Current & 117.5 & $\mathrm{~A}$ \\
\hline Amp turns & 4230 & $\mathrm{~A}-\mathrm{t}$ \\
\hline Conductor area & $4.76^{2}$ & $\mathrm{~mm}^{2}$ \\
\hline \multicolumn{1}{|c|}{ cooling $\varnothing$} & 3.18 & $\mathrm{~m}$ \\
\hline \multicolumn{1}{|c|}{ length } & 144 & $\mathrm{~m}$ \\
\hline \multicolumn{1}{|c|}{ resistance } & 175 & $\mathrm{~m} \Omega$ \\
\hline Voltage & 20.6 & $\mathrm{~V}$ \\
\hline Power & 2.42 & $\mathrm{~kW}$ \\
\hline$\Delta \mathrm{T}$ of water & 8.0 & ${ }^{\circ} \mathrm{C}$ \\
\hline \multirow{2}{*}{ Total Flow } & 4.36 & $\mathrm{~L} / \mathrm{min}$ \\
\cline { 2 - 3 } & 1.15 & $\mathrm{GPM}$ \\
\hline
\end{tabular}

The sextupoles, also manufactured at SigmaPhi have a construction similar to the quadrupoles as shown in figure 3. Non-magnetic end plates support three yoke pieces each containing two poles in an open-sided assembly. The plates also serve as an interface to the girders. One of the finished family 1 sextupoles is shown in figure 4 .

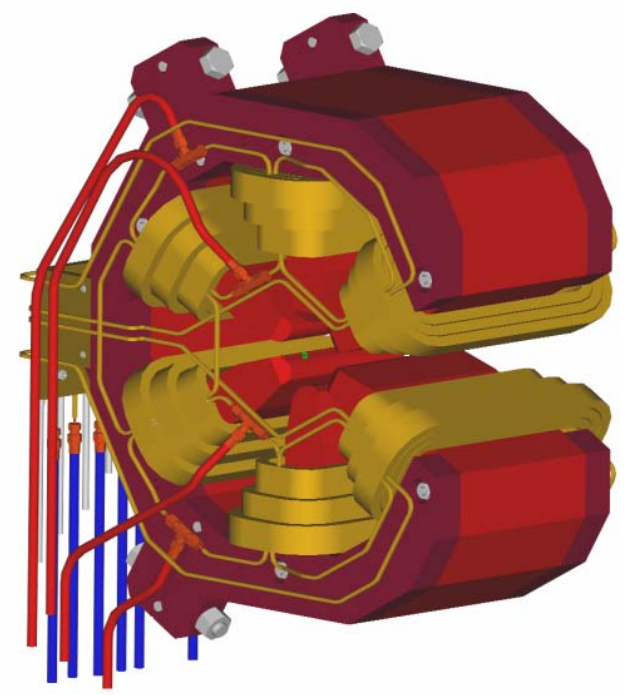

Figure 3. Isometric View of the Sextupole Design.

On average, the sextupole magnets also met the specs defined by eq. (2.). The analysis for the family 1 sextupoles is given in table 3 , where the relative strengths, $I_{n / 3}$ are now w.r.t the sextupole strength $I_{3}$. 


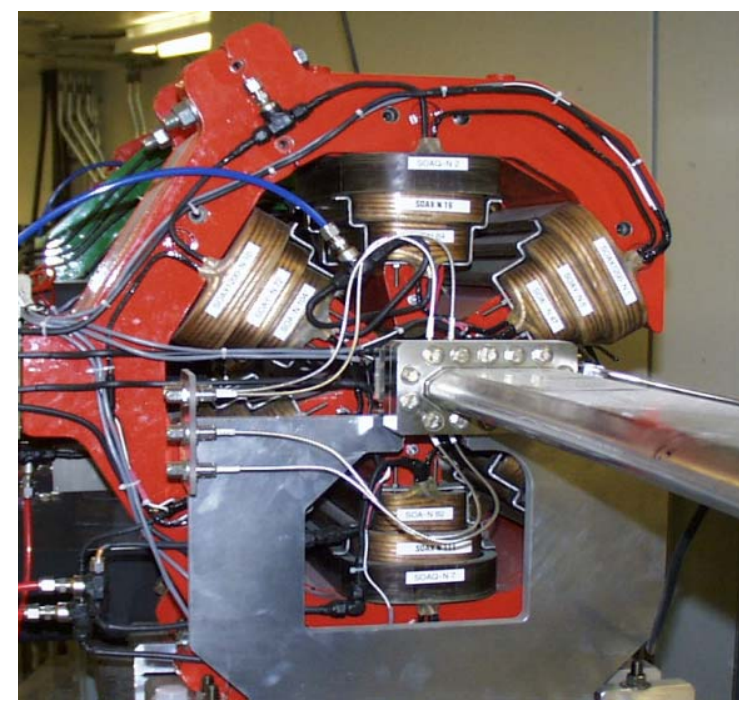

Figure 4. Fabricated Sextupole Magnet (Family 1)

Table 4: Measured Harmonics for Family 1 Sextupoles

\begin{tabular}{|l|l|l|l|l|l|}
\hline $\mathrm{n}$ & & 4 & 5 & 6 & 7 \\
\hline $\mathrm{I}_{\mathrm{n} / 3}$ & & 0.0533 & 4.47 & $2.17 \mathrm{E} 2$ & $3.01 \mathrm{E} 4$ \\
\hline tilt & & 69.64 & 99.92 & -25.85 & 23.40 \\
\hline $\mathrm{n}$ & 8 & 9 & 10 & 11 & 12 \\
\hline $\mathrm{I}_{\mathrm{n} / 3}$ & $9.51 \mathrm{E} 6$ & $1.23 \mathrm{E} 9$ & $4.03 \mathrm{E} 11$ & $8.61 \mathrm{E} 13$ & $2.74 \mathrm{E} 16$ \\
\hline tilt & -15.03 & -7.95 & 0.02 & -7.62 & 35.23 \\
\hline
\end{tabular}

\section{ORBIT CORRECTORS}

The CLS requires 24 combined horizontal/vertical orbit correctors. The corrector parameters are given in table 5 and details of the design are given in ref. [4]. The correctors were built at Budker Institute in Novosibirsk, Russia. A schematic of the corrector is shown in figure 5 and the finished magnet in figure 6 . The two coils on the right drive the vertical field while two sets of coils are used to drive the horizontal field. The harmonic content of the fields was required to satisfy conditions, similar to the sextupole correctors.

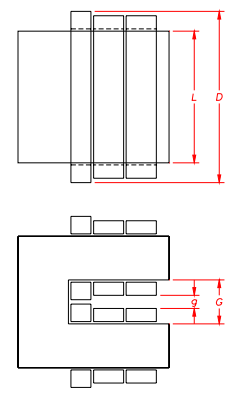

Figure 5. Corrector Schematic.

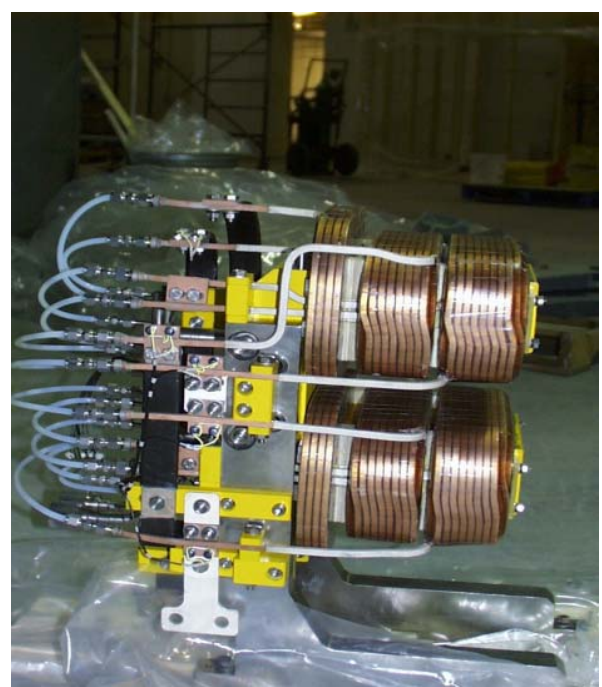

Figure 6. Fabricated Corrector Magnet.

Table 5. Orbit Corrector Design Parameters

\begin{tabular}{|c|c|c|c|c|}
\hline \# Magnets & \multicolumn{3}{|c|}{24} & \\
\hline Yoke length & \multicolumn{3}{|c|}{0.150} & $\mathrm{~m}$ \\
\hline Gap (yoke) G & \multicolumn{3}{|c|}{0.108} & $\mathrm{~m}$ \\
\hline Gap (coils) g & \multicolumn{3}{|c|}{0.044} & $\mathrm{~m}$ \\
\hline X or Y kick & \multicolumn{3}{|c|}{1.4} & mrad \\
\hline Field $B_{y}$ & \multicolumn{3}{|c|}{0.090} & $\mathrm{~T}$ \\
\hline Field $B_{x}$ & \multicolumn{3}{|c|}{0.090} & $\mathrm{~T}$ \\
\hline Coil Function & $B_{y}$ & \multicolumn{2}{|c|}{$B_{x}$} & \\
\hline \# Coils & 2 & 2 & 2 & \\
\hline Turns & 24 & 39 & 36 & $\mathrm{t}$ \\
\hline Current & 180 & 180 & 180 & $\mathrm{~A}$ \\
\hline Amp turns & 4320 & 7020 & 6480 & A-t \\
\hline Conductor area & $6.48^{2}$ & $6.48^{2}$ & $6.48^{2}$ & $\mathrm{~mm}^{2}$ \\
\hline cooling $\varnothing$ & 3.18 & 3.18 & 3.18 & $\mathrm{~mm}$ \\
\hline length & 34.574 & 49.964 & 46.334 & $\mathrm{~m}$ \\
\hline resistance & 18.7 & 27.0 & 25.0 & $\mathrm{~m} \Omega$ \\
\hline Voltage & 3.36 & 4.86 & 4.5 & $\mathrm{~V}$ \\
\hline Power & 605 & 874 & 810 & $\mathrm{~W}$ \\
\hline$\Delta \mathrm{T}$ of water & 3.28 & 5.96 & 5.29 & ${ }^{\circ} \mathrm{C}$ \\
\hline \multirow{2}{*}{ Total flow } & 2.65 & 2.12 & 2.20 & $\mathrm{~L} / \mathrm{min}$ \\
\hline & 0.7 & 0.56 & 0.58 & usGPM \\
\hline
\end{tabular}

\section{REFERENCES}

[1] L. Dallin, "The Canadian Light Source", these proceedings.

[2] L. Dallin et al, "Gradient Dipole Magnets for the Canadian Light Source", EPAC 2002, p. 2340.

[3] L. Dallin, CLS tech. note 5.2.31.2 Rev. 0 "Synchrotron Light Source Magnets", Feb. 11, 2001.

[4] L. Dallin, CLS tech. note 5.2.31.4 Rev. A - "XY Orbit Correctors", May 30, 2000. 